\title{
A STUDY ON CORRELATION OF MEAN PLATELET VOLUME WITH ACUTE EXACERBATION OF CHRONIC OBSTRUCTIVE PULMONARY DISEASE
}

\author{
Vijaykumar Pandiyan'1, Thirumal Gnanaprakasam², Rangaswami Mangalasundaram ${ }^{3}$ \\ ${ }_{1}^{1}$ Assistant Professor, Department of General Medicine, Government Vellore Medical College, Vellore, Tamilnadu. \\ ${ }^{2}$ Assistant Professor, Department of General Medicine, Government Vellore Medical College, Vellore, Tamilnadu. \\ ${ }^{3}$ Assistant Professor, Department of General Medicine, Government Vellore Medical College, Vellore, Tamilnadu.
}

\section{ABSTRACT}

\section{BACKGROUND}

COPD is an epidemic of modern society. It is one of the major causes of morbidity and mortality in the world. It is a well-known thought that one of the main complication of COPD is Pulmonary Embolism. It is mainly because of changes in platelet count and morphology under the chronic influence of inflammatory cytokines.[1,2,3] Meanwhile, this can also be taken as a parameter for determining severity of COPD. ${ }^{[4]}$

\section{MATERIALS AND METHODS}

The descriptive study of 200 patients diagnosed with COPD, admitted in General Medicine Wards at Government Rajaji Hospital, Madurai were selected. Mean platelet volume[5] of each patient was found out with 24 hours of admission. Spirometry was done to assess the severity of COPD and correlation was established between the two.

Statistical Analysis- Correlation coefficient.

Settings and Design- Correlation study.

\section{RESULTS}

From the study, it was found that COPD is more common after 40 years in males, and is strongly associated with smoking. It was also found that there is a strong correlation between spirometry values and mean platelet volume, i.e. when FEV1\% and FEV1/ FVC ratio decreases, the MPV also decreases and when FEV1\% and FEV1/FVC ratio decreases, the platelet count increases.

\section{CONCLUSION}

MPV was significantly decreased in patients with acute exacerbation of COPD ${ }^{[6,7,8]}$ when compared with stable phase of COPD. FEV1, FEV1/ FVC are the main parameters in PFT[9] to determine the severity. MPV in patients with COPD was found to be independent of age, sex, family history, COPD, systemic hypertension and diabetes mellitus. While smoking is an important risk factor. When MPV decreased in severe COPD, platelet count increased.[10] MPV can be used as a prognostic marker for COPD. There was high negative correlation between platelet count and MPV.[11] There was a very high positive correlation between MPV and severity of COPD.

\section{KEYWORDS}

Mean Platelet Volume, Platelet Count, COPD, Pulmonary Embolism.

HOW TO CITE THIS ARTICLE: Pandiyan V, Gnanaprakasam T, Mangalasundaram R. A study on correlation of mean platelet volume with acute exacerbation of chronic obstructive pulmonary disease. J. Evolution Med. Dent. Sci. 2018;7(16):2007-2010, DOI: $10.14260 /$ jemds/2018/451

\section{BACKGROUND}

COPD is an epidemic of modern society. COPD is one of the major causes of morbidity and mortality in the world. Despite the impressive strides in diagnosis and management over the past three decades, COPD continues to be a major public health problem in industrialised world and is becoming an increasingly important health problem in developing countries. Because COPD may strike an individual during the most productive years, it can have profoundly deleterious psychosocial and economic ramifications. It is a well-known thought that one of the main complications of COPD is Pulmonary Embolism. It is mainly because of changes in platelet count and morphology under the chronic

'Financial or Other Competing Interest': None.

Submission 05-03-2018, Peer Review 28-03-2018,

Acceptance 04-04-2018, Published 16-04-2018.

Corresponding Author:

Dr. Thirumal Gnanaprakasam,

\#67, Ottapatti, Nedungal Post,

Kaveri Pattinam, Krishnagiri-635112, Tamilnadu,

E-mail:drvijvek@gmail.com

DOI: $10.14260 /$ jemds $/ 2018 / 451$

influence of inflammatory cytokines. Meanwhile, this can also be taken as a parameter for determining severity of COPD. Wang et al (2013) stated that there is decrease in mean platelet volume ${ }^{[4,12]}$ when there is an exacerbation of COPD. Initially, there is an increase in mean platelet volume when there is stable phase of COPD.

Ulasli et al (2012) suggested that mean platelet volume can be used as a negative acute phase reactant.[1] But it requires further more studies to prove this result. Thus, the role of platelet volume as a predictor for severity of COPD is unresolved and further studies are definitely needed. This study will help to confirm or refute the published reports on platelet volume in COPD.

\section{MATERIALS AND METHODS}

Study Population

- This descriptive study was conducted among 200 patients diagnosed with COPD admitted in General medicine wards at Government Rajaji Hospital, Madurai. 


\section{Inclusion Criteria}

- $\quad$ Patients diagnosed with COPD using GOLD [27] criteria.

- $\quad$ Age above 40 yrs.

- Gender: Both Male and Female.

\section{Exclusion Criteria}

- Diabetes mellitus.

- HTN.

- Asthma.

- Bronchiectasis.

- Active pulmonary tuberculosis.

- Coronary artery disease.(13)

- Systemic inflammatory diseases.

- Pulmonary thromboembolism.

- Medical treatment with anticoagulant statins,(14) angiotensin-converting enzyme inhibitors, acetylsalicylic acid or clopidogrel.

\section{Study Protocol}

200 patients diagnosed with COPD, admitted in General medicine wards at Government Rajaji Hospital, Madurai were selected. Selected socio-economic, clinical and laboratory data[15] were collected from the patients recorded in a proforma. $2 \mathrm{~mL}$ of blood was withdrawn by venepuncture from the patients within $24 \mathrm{hrs}$. of admission to the hospital for assessing MPV (mean platelet volume). The instrument used for analysis was Cobas Micros OT 18 automated haematological analyser.[5,16] Spirometry was done for every patient for diagnosis of COPD and for assessing the severity.

\section{Statistical Analysis}

The data collected during the study was formulated into a master chart in Microsoft Office Excel and statistical analysis was done with the help of computer using statistical software package SPSS V.17 for windows. Using this software, frequencies, range, mean, standard deviation and percentages were calculated. The statistical analysis was done by the calculation of correlation coefficient between the spirometry and MPV.(17)

The average values of mean platelet volume and the standard deviation were calculated in the four groups namely control population with mild, moderate, severe and very severe COPD. To establish that the difference in MPV between these groups is statistically significant, ANOVA (analysis of variance) was carried out. A ' $p$ ' value of $<0.05$ was considered statistically significant.

\section{RESULTS}

In our study $30.5 \%$ cases (61) were between 41 - 50 years, $31.5 \%$ cases (63) were between $51-60$ years, $17.5 \%$ cases (35) were between 61 - 70 years, 16\% cases (32) were between $71-80$ years and $4.5 \%$ cases (9) were between $>80$ years. As we all know, COPD is more common in males.(18) Our study also reveals the same- males $72 \%$ and females $28 \%$. As well documented in other studies, our study also clearly proves the fact of increased incidence in smokers.(19) In our study, 144 cases (72\%) out of 200 cases were smokers. Out of this, $21 \%$ cases had < 20 pack years, $19.5 \%$ cases had 20 - 29 pack years. $17.5 \%$ cases had 30 - 39 pack years. $12.5 \%$ cases had $>40$ pack years. As we all know, there is no significant relation between SHT, T2DM and COPD. Our study showed 53.5\% cases (107) are hypertensives and 40\% (80) cases are diabetics.

\section{Spirometry Values and Severity of COPD}

- $\quad$ FEV1 $<30 \%$ (very severe) $-4.5 \%$ cases (9)

- $\quad$ FEV1 $30-49 \%$ (severe) - $32.5 \%$ cases (65)

- $\quad$ FEV1 $50-79 \%$ (moderate) - $46 \%$ cases (92)

FEV1/FVC Ratio in COPD- The results of FEV1/FVC ratio in COPD in our study is similar to FEV1 values in COPD.

\section{Platelet Count and COPD}

In our study, platelet count $>3$ lakhs are $27.5 \%$ cases, $2-3$ lakhs are $35.5 \%$ cases and $1-2$ lakhs are $37 \%$ cases. In our study, $13.5 \%$ cases had MPV < $8 \mathrm{fL}, 23.5 \%$ cases had $8-9 \mathrm{fL}$, $39.5 \%$ cases had 9-10 fL, $23.5 \%$ cases had > $10 \mathrm{fL}$. As per GOLD criteria FEV1 decreases and FEV1/FVC ratio also decreases when there is increase in severity of COPD. In our study also, it proved the same. If FEV1 < 30\%, the FEV1/FVC is 0.48 and if $\mathrm{FEV}=80 \%$, the FEV1/FVC is 0.7 . In our study-

- In very severe COPD (FEV1 < 30\%), the MPV is $7.78 \mathrm{fL}$

- In severe COPD (FEV1 30\% - 49\%), the MPV is $8.31 \mathrm{fL}$

- In moderate COPD (FEV1 50\% - 79\%), the MPV is $9.73 \mathrm{fL}$

- In mild COPD (FEV1 < 30\%), the MPV is $10.89 \mathrm{fL}$

Thus, in severe COPD Mean Platelet Volume is decreased. The collected values of FEV1, FEV1/FVC ratio, MPV and platelet count are analysed for finding significance between each other. Since there is no controls in our study, correlation coefficient is used for finding significance.

\begin{tabular}{|c|c|c|c|c|}
\hline FEV1 & $\begin{array}{c}\text { No. of } \\
\text { Cases }\end{array}$ & $\begin{array}{c}\text { FEV1/ } \\
\text { FVC }\end{array}$ & $\begin{array}{c}\text { MPV } \\
\text { (fL) }\end{array}$ & $\begin{array}{c}\text { Platelet Count } \\
\text { (lakhs/ cu.mm) }\end{array}$ \\
\hline$<30 \%$ & 9 & 0.48 & 7.78 & 3.47 \\
\hline $30-49 \%$ & 65 & 0.53 & 8.31 & 3.06 \\
\hline $50-79 \%$ & 92 & 0.64 & 9.73 & 1.99 \\
\hline$>80 \%$ & 34 & 0.71 & 10.89 & 1.5 \\
\hline \multicolumn{5}{|c|}{ Table 1 } \\
\hline
\end{tabular}

\begin{tabular}{|c|c|c|c|c|c|c|c|}
\hline $\begin{array}{c}\text { Grading } \\
\text { of } \\
\text { COPD }\end{array}$ & FEV1 & $\begin{array}{c}\text { No. of } \\
\text { Cases }\end{array}$ & $\begin{array}{c}\text { FEV1/ } \\
\text { FVC }\end{array}$ & \multicolumn{2}{|c|}{ MPV (fL) } & \multicolumn{2}{c|}{$\begin{array}{c}\text { Platelet } \\
\text { Count } \\
\text { (cu.mm) }\end{array}$} \\
\hline & & & & Mean & SD & Mean & SD \\
\hline $\begin{array}{c}\text { Very } \\
\text { Severe }\end{array}$ & $<30 \%$ & 9 & 0.48 & 7.78 & 1.24 & 3.47 & 0.96 \\
\hline Severe & $\begin{array}{c}30 \%- \\
49 \%\end{array}$ & 65 & 0.53 & 8.31 & 1.20 & 3.06 & 0.95 \\
\hline $\begin{array}{c}\text { Moderat } \\
\text { e }\end{array}$ & $\begin{array}{c}50 \%- \\
79 \%\end{array}$ & 92 & 0.64 & 9.73 & 1.22 & 1.99 & 0.98 \\
\hline Mild & $>80 \%$ & 34 & 0.71 & 10.89 & 1.23 & 1.5 & 0.97 \\
\hline \multicolumn{7}{|c|}{ Table 2 } \\
\hline
\end{tabular}

\section{Correlation Values Table}

\begin{tabular}{|c|c|c|c|}
\hline & & $\begin{array}{c}\text { Correlation } \\
\text { Coefficient }\end{array}$ & \\
\hline FEV1\% vs & FEV1/FVC & 0.932 & $\begin{array}{c}\text { V. High } \\
\text { Correlation }\end{array}$ \\
\hline FEV1\% vs & Platelet Count & -0.848 & $\begin{array}{c}\text { Neg. High } \\
\text { Correlation }\end{array}$ \\
\hline FEV1\% vs & MPV & 0.893 & $\begin{array}{c}\text { V. High } \\
\text { Correlation }\end{array}$ \\
\hline $\begin{array}{c}\text { FEV1/ FVC vs } \\
\text { Platelet Count }\end{array}$ & -0.762 & $\begin{array}{c}\text { Neg. High } \\
\text { Correlation }\end{array}$ \\
\hline $\begin{array}{c}\text { FEV1/ FVC vs } \\
\text { Platelet Count } \\
\text { vs }\end{array}$ & MPV & 0.892 & $\begin{array}{c}\text { V. High } \\
\text { Correlation }\end{array}$ \\
\hline \multicolumn{4}{|c|}{ Table 3 } \\
$\begin{array}{c}\text { Neg. High } \\
\text { Correlation }\end{array}$ \\
\hline
\end{tabular}




\section{Jemds.com}

It means that

- When FEV1\%, FEV1/ FVC ratio decreases, the MPV also decreases.

- When FEV1\%, FEV1/ FVC ratio decreases, the platelet count increases.

\section{DISCUSSION}

COPD is a major cause of morbidity and mortality in developed countries and is becoming a major problem in developing countries like India. Endogenous and exogenous risk factors like smoking, sex, diabetes mellitus and systemic hypertension significantly increase the progression of COPD. However, they only explain a part of the cases and there may be other relevant risk factors which need to be identified. Large platelets are more reactive, produce more thrombotic factors $(11)$ and aggregate more easily. $(1,4,6,16)$ Documented changes in mean platelet volume in COPD. But all these studies are conducted in limited sample size. So in this study, an attempt was made to find out if any association existed between the platelet size and severity of COPD among Indian population as reports are scanty.

In the study, the ages of the cases are above 40 years. The most number of cases fell between 51 - 60 years. This pattern corresponds to the pattern reported in India, which is as follows. COPD appears decade earlier compared with the age incidence in developed countries and the peak period is attained between 51 - 60 years. In the present study, the relationship between age and MPV was not statistically significant, whereas Funaik et al (1994) found that MPV was significantly increased in patients of advanced age and it was statistically significant. But MPV decreases with age.(5) But our study did not confirm any of the observations made by the above two workers. COPD is common in males. It is mainly due to environmental factors and deleterious effects of smoking. Females generally are affected after menopause. In the present study, MPV was independent of genders. This is in parallel with the observation.(5) It has been noted that smoking is an important factor, which plays a major role in progression and exacerbation of COPD.

In the present study, no statistical relationship was observed between systemic hypertension and MPV. Bath et al (1996) also observed the same in their study. In contrast, Osuna et al (1998) observed a higher MPV in those with systemic hypertension. MPV in patients with diabetes mellitus did not vary from those without diabetes mellitus. Sharpe et al (1993) stated that MPV was significantly increased in diabetic subjects compared with non-diabetics. They stated that since platelet size is a determinant of platelet function with larger platelets being more reactive per unit volume, the platelets might play a role in micro- and macro-vascular complications of diabetes mellitus. The fact that in our study no relationship was observed may be due to inflammatory cytokines in COPD.

As per GOLD guidelines (2010) for defining COPD, FEV1 should be $\leq 80 \%$. In our study, most of the cases having FEV1 values ranging from $30 \%-79 \%$. Hence, there is a high correlation between severity of COPD and FEV1. Our study has statistically documented this fact. The FEV1/ FVC ratio is also one of the criteria for defining COPD.(9) In our study, the FEV1/ FVC ratio ranges from $0.5-0.69$. Thus, statistically proving that there is a relation between FEV1/ FVC ratio and severity of COPD.

\section{Original Research Article}

Wang et al (2013) quoted that platelet size is increased in stable phase of COPD, but is drastically decreased in acute exacerbation of COPD. In our study MPV decreases when the FEV1 value decreases, thus proving the fact that MPV decreases in acute exacerbation of COPD. Ulasli et al (2012) told that MPV can be used as a negative phase reactant for COPD just like other inflammatory conditions. In our study also, this statement is proved as MPV decreases in acute exacerbation of COPD. In our study, there is very high positive correlation between FEV1 and FEV1/ FVC ratio, FEV1/ FVC ratio and MPV proving that all decreases with severity of COPD. Also, there is very high negative correlation between FEV1, FEV1/ FVC ratio and platelet count. Thus, MPV can be used as a prognostic indicator and determinant of severity of COPD is well proved statistically in our study.

\section{Limitations}

1. We documented significance using correlation coefficient only. We did not do multivariate analysis using ANOVA.

2. Mathematical analysis by way of log probability studies among platelet volume and platelet count was not attempted.

\section{Areas of Further Work}

1. MPV studies in other inflammatory conditions.

2. Follow-up study of MPV after the onset of clinical events and finding out association between MPV and platelet count by applying the log probability formula.

3. Platelet volume studies among patients on inhaled corticosteroids.

4. In vitro studies on factors contributing for thrombomegaly in order to introduce interventional measures.

5. Studies to find out the physiological mechanisms, which regulate MPV within the megakaryocytes.

\section{CONCLUSION}

- MPV was significantly decreased in patients with acute exacerbation of COPD (7.78 femtolitres) when compared with stable phase of COPD (10.89 femtolitres).

- FEV1, FEV1/ FVC are the main parameters in PFT to determine the severity.

- $\quad$ MPV in patients with COPD was found to be independent of age, sex, family history COPD, systemic hypertension and diabetes mellitus. While smoking is an important risk factor.

- When MPV decreased in severe COPD, platelet count increased.

- $\quad$ MPV can be used as a prognostic marker for COPD.

- There was high negative correlation between platelet count and MPV.

- $\quad$ There was a very high positive correlation between MPV and severity of COPD.

\section{REFERENCES}

[1] Ulasli SS, Ozyurek BA, Yilmaz EB, et al. Mean platelet volume as an inflammatory marker in acute exacerbation of chronic obstructive pulmonary disease. Pol Arch Med Wewn 2012;122(6):284-90. 


\section{Jemds.com}

[2] Pepys MB, Hirschfield GM. C-reactive protein: a critical update. J Clin Invest 2003;111(12):1805-12.

[3] de Torres JP, Cordoba-Lanus E, López-Aguilar C, et al. C-reactive protein levels and clinically important predictive outcomes in stable COPD patients. Eur Respir J 2006;27(5):902-7.

[4] Wang RT, Li JY, Cao ZG, et al. Mean platelet volume is decreased during an acute exacerbation of chronic obstructive pulmonary disease. Respirology 2013;18(8):1244-8.

[5] Bancroft AJ, Abel EW, Mclaran M. Mean platelet volume is a useful parameter: a reproducible routine method using a modified coulter thrombocytometer. Platelets 2000;11(7):379-87.

[6] Bansal R, Gupta HL, Goel A. Association of increased platelet volume in patients of chronic obstructive pulmonary disease: clinical implications. JIACM 2002;3(2):169-72.

[7] Fogarty AW, Jones S, Britton JR, et al. Systemic inflammation and decline in lung function in a general population: a prospective study. Thorax 2007;62(6):515-20.

[8] Malo O, Sauleda J, Busquets X, et al. Systemic inflammation during exacerbations of chronic obstructive pulmonary disease. Arch Bronconeumol 2002;38(4):172-6.

[9] Swanney MP, Miller MR. Adopting universal lung function reference equations. Eur Respir J 2013;42(4):901-3.

[10] Biljak VR, Pancirov D, Cepelak I, et al. Platelet count, mean platelet volume and smoking status in stable chronic obstructive pulmonary disease. Platelets 2011;22(6):466-70.

\section{Original Research Article}

[11] Martin JF, Trowbridge EA, Salmon GL, et al. The relationship between platelet and megakaryocyte volumes. Thromb Res 1982;28(4):447-59.

[12] Corash L. The relationship between megakaryocyte ploidy and platelet volume. Blood cells 1989;15(1):81107.

[13] De Luca G, Santagostino M, Secco GG, et al. Mean platelet volume and extent of coronary artery disease: results from a large prospective study. Atherosclerosis 2009;206(1):292-7.

[14] Kaczmarek P, Sladek K, Skucha W, et al. The influence of simvastatin selected inflammatory markers in patients with chronic obstructive pulmonary disease. Pol Arch Med Wewn 2010;120(1-2):11-7.

[15] Zhang YJ. 3-D image analysis system and megakaryocyte quantification. Cytometry 1991;12(4):308-15.

[16] Haver VM, Gear AR. Functional fractionation of platelets. J Lab Clin Med 1981;97(2):187-204.

[17] Stevenson NJ, Walker PP, Costello RW, et al. Lung mechanism and dyspnea during exacerbations of chronic obstructive pulmonary disease. Am J Respir Crit Care Med 2005;172(12):1510-6.

[18] Tantucci C, Donati P, Nicosia F, et al. Inspiratory capacity predicts mortality in patients with chronic obstructive pulmonary disease. Respir Med 2008;102(4):613-9.

[19] Gan WQ, Man SF, Sin DD. The interactions between cigarette smoking and reduced lung function on systemic inflammation. Chest 2005;127(2):558-64. 